\title{
Cerebral blood flow increases over the first three days of life in extremely preterm neonates
}

\author{
Judith H Meek, Lidia Tyszczuk, Clare E Elwell, J S Wyatt
}

\begin{abstract}
Aim-To measure changes in cerebral haemodynamics over the first three days of life in very preterm infants with normal brains.

Methods-Eleven mechanically ventilated infants (median gestational age 26 weeks) without evidence of major abnormalities on cranial ultrasound examination were studied. Cerebral blood flow (CBF) and cerebral blood volume (CBV) were measured using near infrared spectroscopy at least twice over the first three days of life. Results-Cerebral blood flow increased significantly with time $(p=0.02$; stepwise linear regression) and this was independent of mean arterial blood pressure, $\mathrm{PaCO}_{2}$, and haematocrit.

Conclusion-This change is likely to represent a normal adaptive response of the cerebral circulation to postnatal life.

(Arch Dis Child Fetal Neonatal Ed 1998;78:F33-F37)
\end{abstract}

Keywords: cerebral blood flow; cerebral haemodynamics; near infrared spectroscopy; extremely preterm

Periventricular haemorrhage and hypoxiaischaemia are the most common causes of disabling brain injury in very preterm infants, and the pathogenesis of both types of injury is likely to be associated with abnormalities of cerebral perfusion in the critical first few days after delivery. An early study by Lou et $a l^{1}$ showed an increased risk of neurodevelopmental abnormalities in infants with cerebral blood flow $(\mathrm{CBF}$ ) of less than $20 \mathrm{ml} / 100 \mathrm{~g} / \mathrm{min}$ measured a few hours after birth. More recent studies have shown that intact survival is possible despite CBF measurements lower than 10 $\mathrm{ml} / \mathrm{kg} / \mathrm{min},{ }^{2} 3$ and the critical minimum level of $\mathrm{CBF}$ required to maintain cellular integrity has not yet been defined. Improvements in neonatal intensive care, leading to a reduction in cerebral injury, will depend on a better understanding of the normal adaptive changes of the cerebral circulation during the most vulnerable period, the first three days of life. ${ }^{4}$

The aim of this study was to define normal changes in global CBF and cerebral blood volume (CBV) by making repeated measurements with near infrared spectroscopy in a group of very preterm infants with apparently normal brains, during the first three days of life. The infants selected for study were undergoing intensive care, but were of appropriate weight for gestational age and had no evidence of significant antenatal or perinatal brain injury on the basis of cranial ultrasound appearances.

\section{Methods}

Eleven very preterm infants undergoing intensive care in the neonatal unit at University College London Hospitals Trust were studied. Their median gestational age was 26 (range 24-31) weeks and the median birthweight was 825 (range 637-1460) g. All infants were appropriately grown for gestational age (birthweight above the 10th centile). Seven had normal cranial ultrasound imaging at the time of study and on subsequent examination, three had small intraventricular haemorrhages which were first observed on the second day of life and which subsequently resolved, and one had mild ventricular dilatation by term with no evidence of preceding haemorrhage. Clinical details of the study infants are given in table 1 . Each infant was intubated for resuscitation shortly after birth, and ventilated with supplementary oxygen. When studied, all infants were receiving conventional mechanical ventilation via an endotracheal tube, and physiological variables including mean arterial blood pressure (MABP) and transcutaneous carbon dioxide tension were monitored continuously during each study. Small transient fluctuations in $\mathrm{FIO}_{2}$ were induced by the research staff (JM and LT) for the measurement of CBF and $\mathrm{CBV}$, but the ventilator settings and the clinical management of each infant was the responsibility of the attending clinicians in the neonatal unit. Each infant was studied on two or more occasions during the first three days of life, and none of the studies started within an hour of the administration of surfactant. The study was approved by the hospital research ethics committee and informed consent was obtained from one or both parents of each infant before enrolment.

Simultaneous measurements of arterial saturation $\left(\mathrm{SaO}_{2}\right)$ were obtained, using a pulse oximeter (Nellcor N200), and of MABP, using a transducer in an indwelling umbilical or peripheral arterial catheter (HP 78834A, Hewlett Packard), or by an oscillometric technique using an inflatable cuff (Dinamap 1846SX, Critikon). Continuous estimates of arterial oxygen tension $\left(\mathrm{PaO}_{2}\right)$ and carbon dioxide tension $\left(\mathrm{PaCO}_{2}\right)$ were obtained using a transcutaneous monitor (Hewlett Packard 3428G03410) calibrated with arterial blood gas samples. The arterial haemoglobin concentration and haematocrit of each infant were measured on the day of each study. Cranial ultrasound scans (Ultramark 4, Advanced Technical Laboratories, Letchworth, UK) were performed daily for the first week of life and then weekly until term or discharge from hospital. 
The theory of near infrared spectroscopy has been described in detail elsewhere. ${ }^{5}$ In brief, it depends on the relative transparency of biological tissue to near infrared light, and the absorption of light by oxyhaemoglobin $\left(\mathrm{HbO}_{2}\right)$ and deoxyhaemoglobin. A modification of the Beer Lambert law is used to convert measured changes in optical density to changes in chromophore concentration. In this study measurements were obtained using a commercial spectrophotometer (NIRO500 or NIR1000, Hamamatsu Photonics KK, Japan). Near infrared light from four (NIRO500) or six (NIR1000) laser diodes was transmitted via a fibre optic bundle to an "optode" on the tempero-parietal or frontal region of the infant's head. A detecting optode placed $4-5 \mathrm{~cm}$ away on the opposite side of the head was connected to a second fibre optic bundle which conveyed the emerging light to the spectrophotometer. A controlling computer converted the changes in optical density into changes in cerebral $\left[\mathrm{HbO}_{2}\right]$ and $[\mathrm{Hb}]$ while simultaneously recording $\mathrm{SaO}_{2}$, MABP, $\mathrm{PaCO}_{2}$ and heart rate.

Cerebral blood flow was determined from the Fick principle, using $\mathrm{HbO}_{2}$ as an intravascular tracer. ${ }^{6}$ A rapid rise (over 2 to 5 seconds) in $\mathrm{SaO}_{2}$ was induced by a step increase in $\mathrm{FIO}_{2}$. Cerebral blood flow in $\mathrm{ml} / 100 \mathrm{~g} / \mathrm{min}$ was then calculated from the integral of the saturation rise and the rate of rise of tracer concentration using the equation:

$$
\mathrm{CBF}=\kappa . \Delta\left[\mathrm{HbO}_{2}\right] /\left(\mathrm{H} . \int \Delta \mathrm{SaO}_{2} . \mathrm{dt}\right)
$$

where $\kappa$ is a constant (0.0614) incorporating brain tissue density and the molecular weight of haemoglobin and $\mathrm{H}$ is the large vessel haemoglobin concentration in $\mathrm{g} / \mathrm{dl}$.

Cerebral blood volume was measured using the indicator dilution technique with a slow small change (over 1 to 2 minutes) in arterial oxygen saturation within the range $92 \%$ to $98 \%$ by manipulation of the $\mathrm{FIO}_{2}$ and determining the resulting change in $\left[\mathrm{HbO}_{2}\right]$ concentration. CBV was then obtained from the equation:

$$
\mathrm{CBV}=\kappa . \Delta\left[\mathrm{HbO}_{2}\right] /\left(\Delta \mathrm{SaO}_{2} \times \mathrm{H} \times \mathrm{R}\right)^{7}
$$

where $\mathrm{R}(0.69)$ is the large vessel:cerebral haematocrit ratio. As it was not possible to induce a suitable change in $\mathrm{SaO}_{2}$ in infants who were ventilated either in air or in $100 \%$ oxygen, no measurements were attempted in these infants.

On each day of the study six measurements of CBF were attempted. Only those measurements were accepted that met previously established criteria for the stability of parameters such as the $\mathrm{PaCO}_{2}, \mathrm{MABP}$, and $[\mathrm{Hb}+$ $\mathrm{HbO}_{2}$ ] during the measurement, and the stability of the $\mathrm{SaO}_{2}$ before the measurement. ${ }^{8}$ The mean value of all the measurements which met the acceptance criteria was calculated on each day. Similarly, six measurements of CBV were attempted each day. The number of successful measurements of both CBF and CBV on each day ranged between two and six, although one infant had no acceptable CBV measurements on day 2 .

As part of ongoing follow up, infants were assessed between 12 and 18 months of corrected age. The assessment included both medical and structured neurological examinations ${ }^{9}$ and were carried out by a paediatrician blind to the results of the near infrared spectroscopy studies. Particular attention was paid to hearing and visual responses. Infants were categorised according to the presence or absence of neurological impairments from the results of these examinations. The impaired infants were further subdivided into those with and those

\begin{tabular}{|c|c|c|c|c|c|c|c|}
\hline $\begin{array}{l}\text { Case } \\
\text { No }\end{array}$ & $\begin{array}{l}\text { Gestational } \\
\text { age (weeks) }\end{array}$ & $\begin{array}{l}\text { Birthweight } \\
(g)\end{array}$ & Clinical details & Inotropes & $\begin{array}{l}\text { Cranial } \\
\text { ultrasound at } \\
\text { time of study }\end{array}$ & $\begin{array}{l}\text { Cranial } \\
\text { ultrasound at } \\
\text { term }\end{array}$ & Outcome $12-18$ months \\
\hline 1 & 24 & 864 & $\begin{array}{l}\text { Spontaneous preterm labour, } \\
\text { maternal candida amnionitis, } \\
\text { mild hyaline membrane disease }\end{array}$ & No & Small L IVH & Normal & Normal \\
\hline 2 & 24 & 810 & $\begin{array}{l}\text { Spontaneous preterm labour, } \\
\text { mild hyaline membrane disease }\end{array}$ & No & Normal & Normal & Squint related to ROP \\
\hline 3 & 25 & 767 & $\begin{array}{l}\text { Spontaneous preterm labour, } \\
\text { mild hyaline membrane disease }\end{array}$ & No & Normal & Normal & Normal \\
\hline 4 & 28 & 1130 & $\begin{array}{l}\text { Ruptured membranes } 5 \text { weeks, } \\
\text { spontaneous labour, } \\
\text { mild hyaline membrane disease }\end{array}$ & No & Normal & Normal & Phasic ankle response \\
\hline 5 & 24 & 700 & $\begin{array}{l}\text { Small placental abruption, } \\
\text { vaginal delivery, } \\
\text { mild hyaline membrane disease }\end{array}$ & No & Small R IVH & Normal & $\begin{array}{l}\text { Died } \\
\text { Necrotising enterocolitis }\end{array}$ \\
\hline 6 & 27 & 1100 & $\begin{array}{l}\text { Twin } 1 \text {, } \\
\text { spontaneous preterm labour, } \\
\text { moderate hyaline membrane disease }\end{array}$ & Dopamine day 1 & Normal & Normal & Normal \\
\hline 7 & 27 & 990 & $\begin{array}{l}\text { Spontaneous preterm labour, } \\
\text { mild hyaline membrane disease }\end{array}$ & No & Normal & Normal & Normal \\
\hline 8 & 26 & 825 & $\begin{array}{l}\text { Maternal PIH } \\
\text { emergency Section, poor CTG, } \\
\text { cord } \mathrm{pH}=6.8 \text {, } \\
\text { moderate hyaline membrane disease }\end{array}$ & No & Small R IVH & Normal & Asymmetry of ankle tone \\
\hline 9 & 24 & 637 & $\begin{array}{l}\text { Breech delivery, maternal vaginal } \\
\text { chlamydia, moderate hyaline } \\
\text { membrane disease }\end{array}$ & No & Normal & $\begin{array}{l}\text { Mild ventricular } \\
\text { dilation }\end{array}$ & Normal \\
\hline 10 & 31 & 1443 & $\begin{array}{l}\text { Elective caesarean section, } \\
\text { maternal cranio-pharyngioma, } \\
\text { severe hyaline membrane disease }\end{array}$ & No & Normal & Normal & Emigrated, lost to follow up \\
\hline 11 & 30 & 1460 & $\begin{array}{l}\text { Emergency caesarean section, } \\
\text { ante-partum haemorrhage, } \\
\text { first pH 7.22, } \\
\text { moderate hyaline membrane disease }\end{array}$ & No & Normal & Normal & $\begin{array}{l}\text { Subtle neurological } \\
\text { abnormalities }\end{array}$ \\
\hline
\end{tabular}

Table 1 Clinical details of study infants 
without functional disability. Impairments without disability between 12 and 18 months of corrected age were usually subtle abnormalities of tone, posture, or reflexes. ${ }^{10}$

As the distributions of CBF each day were positively skewed, the logarithm of the values was used for further analysis. The dependence of $\log \mathrm{CBF}$ and $\mathrm{CBV}$ on time, $\mathrm{PaCO}_{2}, \mathrm{MABP}$, haematocrit, infant number and gestational age were tested using stepwise multiple linear regression analysis (Sigmastat version 2.0, Jandel, California, USA).

\section{Results}

Six out of 11 infants had satisfactory measurements on each day of the study, and the remainder were studied on two out of the three days. Figure 1 shows CBF for each infant compared with postnatal age. Stepwise multiple linear regression analysis (using a dummy variable for each infant) demonstrated the dependence of $\log \mathrm{CBF}$ on time $(\mathrm{p}=0.02)$ and gestational age $(\mathrm{p}<0.001)$, but not on $\mathrm{PaCO}_{2}$, MABP, haematocrit or infant number.

Five out of 11 infants had satisfactory measurements of CBV on each day of the study, five on two days, and one on a single occasion. The variation of $\mathrm{CBV}$ with time is shown in fig 2 . There was no relation of $\log \mathrm{CBV}$ with time or any physiological variable. Figs 3-5 show the

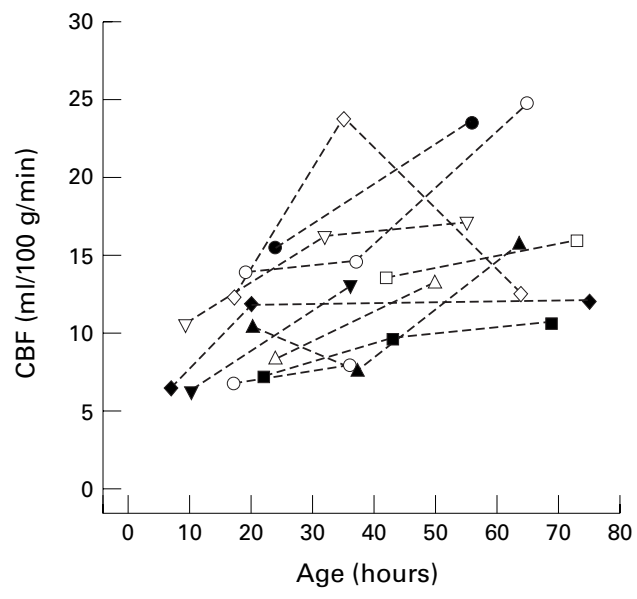

Figure 1 Variation in $C B F$ with postnatal age: symbols indicate individual infants.

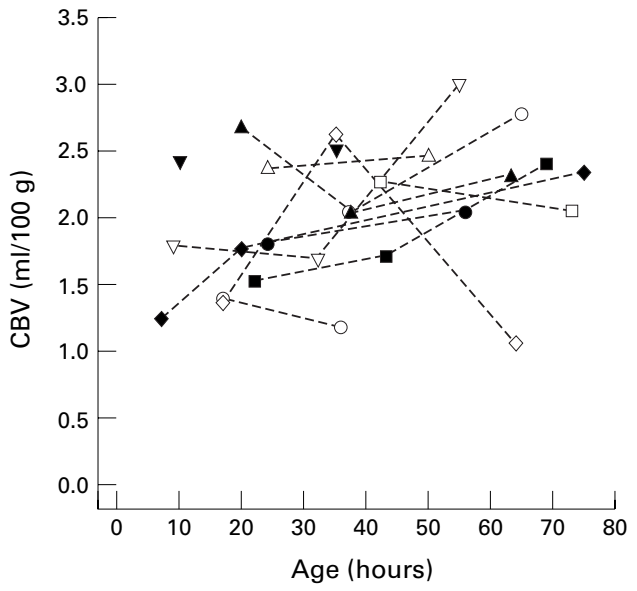

Figure 2 Variation in $C B V$ with postnatal age.

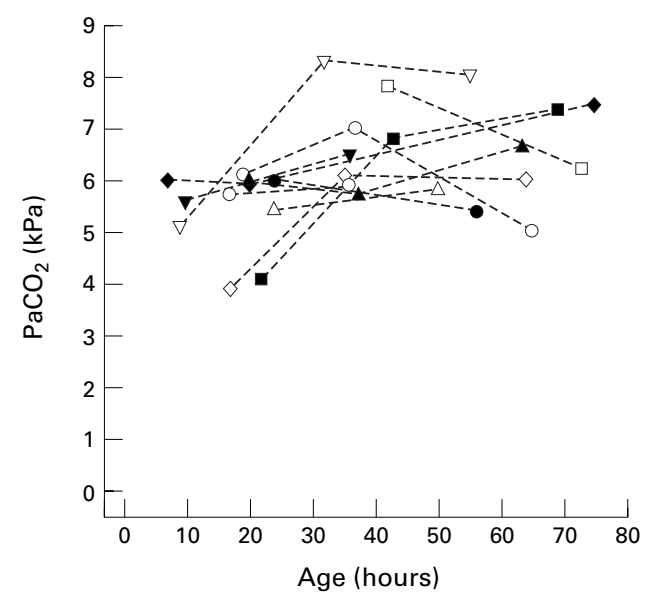

Figure 3 Variation in $\mathrm{PaCO}_{2}$ with postnatal age.

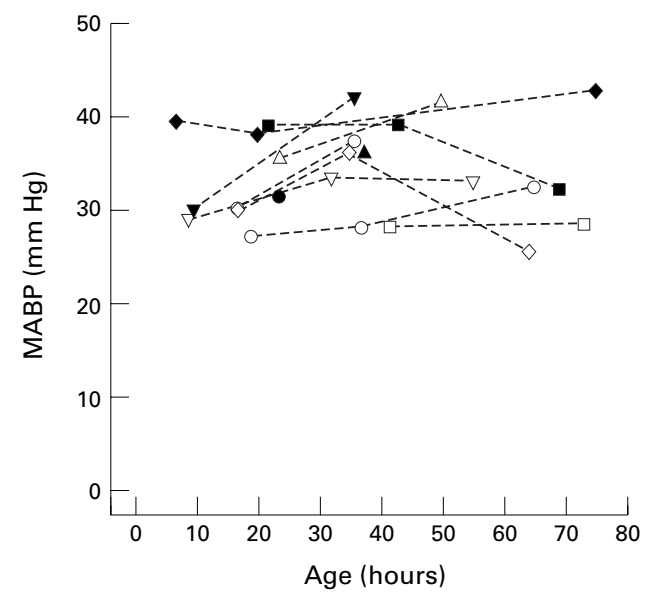

Figure 4 Variation in $M A B P$ with postnatal age.

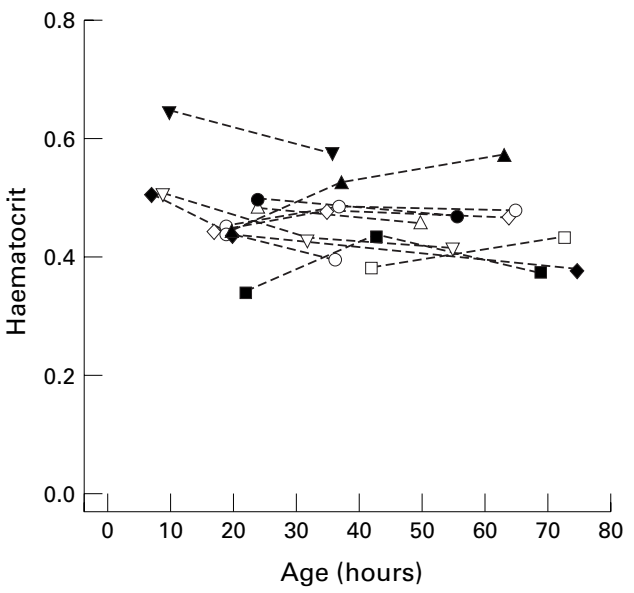

Figure 5 Variation in haematocrit with postnatal age.

variation of $\mathrm{PaCO}_{2}, \mathrm{MABP}$, and haematocrit with time. The ventilator settings (mean airway pressure and $\mathrm{FIO}_{2}$ ) were not significantly different over each of the three days.

All infants had normal brains on cranial ultrasound examination at a corrected age of term, or before discharge from the neonatal unit, except case 9, who had mild ventricular dilatation. This infant had an unusually high $\mathrm{CBF}$ and CBV on day 2.

Nine out of 11 infants were examined between 12 and 18 months of age (corrected 
for prematurity) and no disabling neurodevelopmental abnormalities were detected, although three infants displayed subtle abnormalities of tone. One infant died of necrotising enterocolitis and one was lost to follow up. The outcome data are summarised in table 1 .

\section{Discussion}

The range of $\mathrm{CBF}$ we observed during the first 24 hours was wide $(6.3-15.2 \mathrm{ml} / 100 \mathrm{~g} / \mathrm{min})$, comparable with values measured by Pryds in the first 2 hours of life using the Xenon clearance technique $(5.2-18.7 \mathrm{ml} / 100 \mathrm{~g} / \mathrm{min}) .{ }^{11}$ Altman obtained a range of $4.7-17 \mathrm{ml} / 100 \mathrm{~g} / \mathrm{min}$ using positron emission tomography (PET) in preterm neonates 1 to 6 days old. ${ }^{2}$ The coefficients of variation among subjects were of $34 \%$, $41 \%$, and $31 \%$ on the three consecutive days, comparable with that of $34 \%$ measured in adults using near infrared spectroscopy. ${ }^{12}$

There is no gold standard method of measuring $\mathrm{CBF}$ in human neonates. The near infrared spectroscopy technique has been compared with the intravenous ${ }^{133}$ Xenon clearance method in human neonates undergoing intensive care. $^{1314}$ Good correlations were observed between the two methods except at high values of $\mathrm{CBF}$ where the near infrared spectroscopy estimate of CBF was slightly lower than that obtained by the Xenon method. Near infrared spectroscopy is noninvasive and repeatable, but cannot be used to measure $\mathrm{CBF}$ when infants are ventilated either in air or $100 \% \mathrm{O}_{2}$, when it is not possible to make small changes in $\mathrm{SaO}_{2}$ by adjusting the $\mathrm{FIO}_{2}$. This resulted in some infants being studied only on two out of the three days.

The technique of measuring CBV has not been validated independently in human newborns, but the values of CBV we obtained are similar to those observed using $\mathrm{PET}^{2}$ Although some discrepancies have been observed in CBV measurements following a change in $\mathrm{PaCO}_{2}{ }^{15}$ there is no evidence of systematic errors which would invalidate the measurements we obtained.

We have shown a significant rise in CBF over the first three days of life in very preterm infants undergoing intensive care, consistent with measurements using the Xenon clearance method. ${ }^{16}$ Doppler ultrasound measurements of cerebral artery velocities have demonstrated an initial decrease over the first 5 hours of life, followed by a gradual increase. ${ }^{17}{ }^{18}$ However, these velocity measurements are hard to interpret because of the possibility of alterations in the diameter of the insonated vessels.

Our results strongly suggest that the increase in CBF represents a normal adaptive response of the cerebral circulation to postnatal life rather than being a direct result of changes in MABP, $\mathrm{PaCO}_{2}$, or haematocrit. Measurements of $\mathrm{CBF}$ using the Xenon technique have suggested that the increase with postnatal age is correlated with changes in $\mathrm{PaCO}_{2}$ and is inversely correlated with blood haemoglobin concentration. ${ }^{16}$ Other studies have suggested that $\mathrm{CBF}$ is also determined by the oxygen affinity of the circulating haemoglobin ${ }^{19}$ and by the oxygen tension achieved at resuscitation after delivery. ${ }^{20}$ In this study haemoglobin concentration was not used as an independent variable, being part of the denominator of the equations used to calculate $\mathrm{CBF}$ and CBV. Therefore, the haematocrit was used as a physiological variable related to $\mathrm{CBF}$. We found no independent association between $\mathrm{CBF}$ and haematocrit. The viscosity of blood is generally thought to vary inversely with haematocrit. Linderkamp et $a l^{1}$ have measured the viscosity of blood samples from newborn infants with gestational ages between 24 weeks and term, using glass tubes of varying diameters. They showed that for a given haematocrit the viscosity varies with both the tube size and the gestational age of the neonate. Therefore, the expected contribution of changes in haematocrit to the increase of $\mathrm{CBF}$ with time in a group of neonates of different gestational ages is uncertain. CBF was inversely related to gestational age, but the importance of this finding in a small group of subjects is doubtful. MABP in the group did not increase with postnatal age, contrary to trends noted in other studies. ${ }^{16}$ This may have been a reflection both of the small sample size, and of the policy in our unit of tolerating relatively low blood pressures in infants who are clinically well perfused. $\mathrm{CBF}$ was independent of MABP, suggesting that autoregulation of the cerebral circulation was intact in this group of infants. The rise in $\mathrm{CBF}$ with time was not associated with an increase in $\mathrm{CBV}$, indicating a reduction in transit time.

The increase in cerebral perfusion with time is likely to be due to an increase in left ventricular output, coupled with a reduction in cerebrovascular resistance. An increase in left ventricular output has been observed in term neonates studied over the first few days of life by Doppler echocardiography, ${ }^{22}{ }^{23}$ although there is evidence that the presence of lung disease can affect the time course of this change. ${ }^{24}$ Increasing left and right ventricular outputs have also been seen in premature ventilated infants, ${ }^{25}$ with low cardiac outputs related to higher mean airway pressures and larger ductal shunts. The rise in cardiac output may be a consequence of lowered peripheral vascular resistance in several organs including the brain.

The resulting increase in $\mathrm{CBF}$ is seen in infants with normal brains, and further studies are under way to investigate whether deviations from this response are associated with an increased risk of perinatal brain injury.

This work was supported by a grant from the United Kingdom Medical Research Council.

We thank Professor David Edwards, Ms Jan Townsend, and Drs Ann Stewart, Simon Roth, David McCormick and Vincent Drs Ann Stewart, Simon Roth, David McCorm
Kirkbride for their contribution to this work.

1 Lou HC, Skov H, Pederson H. Low cerebral blood flow: A risk factor in the neonate. $\mathcal{F}$ Pediatr 1979;95:606-9.

2 Altman DI, Perlman J, Volpe JJ, Powers WJ. Cerebral oxygen metabolism in newborns. Pediatrics 1993;92:99-104.

3 Lou HC, Skov H, Henrikson L. Intellectual impairment with regional cerebral dysfunction after low neonatal cerebral blood flow. Acta Paediatr Scand 1989;Suppl 360:72-82.

4 Thorburn RJ, Lipscomb AP, Stewart AL, Reynolds EOR, Hope PL. Timing and antecedents of periventricular hoemorrhage and of cerebral atrophy in very preterm infants. Early Hum Dev 1982;7:221-38. 
5 Cope M, Delpy DT. A system for the long-term measurement of cerebral blood and tissue oxygenation in Biol Eng Comput 1988;26:289-94.

6 Edwards AD, Wyatt JS, Richardson C, Delpy DT, Cope M, Reynolds EOR. Cotside measurement of cerebral blood flow in ill newborn infants by near infrared spectroscopy. Lancet 1988;ii: $770-1$

7 Wyatt JS, Cope M, Delpy DT, et al. Quantitation of cerebral blood volume in human infants by near-infrared spectroscopy. I Appl Physiol 1990;68: 1086-91.

8 Elwell CE. A practical user's guide to near infrared spectroscopy. Hamamatsu Photonics, Japan 1995.

9 Amiel-Tison C, Stewart A. Follow up studies during the first five years of life: a pervasive assessment of
neurological function. Arch Dis Child 1989;64: 496-502.

10 Roth SC, Baudin J, Pezzani-Goldsmith M, Townsend J, Reynolds EOR, Stewart AL. Relation between neurodevelopmental status of very preterm infants at one and eight velopmental status of very preterm infants at on

11 years. Dev Med Child Neurol 1994;36:1049-62. cerebral blood flow and plasma epinephrine in hypoglycaemic, preterm neonates. Pediatrics 1990;85:172-6.

12 Elwell CE, Cope M, Edwards AD, Wyatt JS, Delpy DT, Reynolds EOR. Quantification of adult cerebral haemodynamics by near infrared spectroscopy. F Appl Physiol 1994;77:2753-60.

13 Bucher HU, Lipp AF, Duc D, Edwards AD. Comparison between ${ }^{133}$ Xenon clearance and near infrared spectroscopy for estimation of cerebral blood flow in sick preterm infants. Pediatr Res 1993;33:56-60.

14 Skov L, Pryds O, Greisen G. Estimating cerebral blood flow in newborn infants: comparison of near infrared spectroscopy and ${ }^{133} \mathrm{Xe}$ clearance. Pediatr Res 1991;30:570-3.

15 Brun NC, Greisen G. Cerebrovascular response to carbon dioxide as detected by nearinfrared spectrophotometry: comparison of three different measures. Pediatr Res 1994;36:20-4.
16 Pryds $\mathrm{O}$, Greisen $\mathrm{G}$. Effect of $\mathrm{PaCO}_{2}$ and haemoglobin concentration on day to day variation of cerebral blood flow in preterm neonates. Acta Paediatr Scand 1989;Suppl 360:33-6.

17 Winberg P, Sonesson SE, Lundell BPW. Postnatal changes in intracranial blood flow velocity in preterm infants. Acta Paediatr Scand 1990;79:1150-5.

18 Hayashi T, Ichiyama T, Uchida M, Tashira N, Tanaka H. Evaluation by colour Doppler and pulsed Doppler sonography of blood flow velocities in intracranial arteries during the early neonatal period. Eur $f$ Pediatr 1992;151:461-5.

19 Lipp-Zwahlen AK, Muller A, Tuchschmid P, Duc G. Oxygen affinity of haemoglobin modulates cerebral blood flow in preterm infants. A study with the non-invasive flow in preterm infants. A study with the non-invasive 360:26-32.

20 Lundstrom KE, Pryds O, Greisen G. Oxygen at birth and prolonged cerebral vasoconstriction in preterm infants. Arch Dis Child 1995;72:F81-F6.

21 Linderkamp O, Stadler AA, Zilow EP. Blood viscosity and optimal haematocrit in preterm and full-term neonates in optimal haematocrit in preterm and full-term neo
50- to 500-um tubes. Pediatr Res 1992;32:97-102.

22 Mandelbaum V, Alverson D, Kirchgessner A, Linderkamp O. Postnatal changes in cardiac output and haemorrheology in normal neonates born at full term. Arch Dis Child 1991;66:391-4.

23 Agata Y, Hiraishi S, Oguchi K, et al. Changes in left ventricular output from fetal to early neonatal life. $\mathcal{F}$ Pediatr 1991;119:441-5.

24 Walther FJ, Benders MJ, Leighton JO. Early changes in the neonatal circulatory transition. F Pediatr 1993;123:625-32.

25 Evans N, Kluckow M. Early determination of right and left ventricular output in ventilated preterm infants. Arch Dis Child 1996;74:F88-F94. 